\begin{tabular}{|c|l|}
\hline Title & $\begin{array}{l}\text { Design of Mesoporous Silica/Cytosine - Phosphodiester - Guanine Oligodeoxynucleotide Complexes To Enhance } \\
\text { Delivery Efficiency }\end{array}$ \\
\hline Author(s) & Zhu, Y ufang; Meng, Wenjun; Li, Xianglan; Gao, Hong; Hanagata, Nobutaka \\
\hline Citation & $\begin{array}{l}\text { The Journal of Physical Chemistry C, 115(2), 447-452 } \\
\text { https://doi.org/L0.1021/p109535d }\end{array}$ \\
\hline Issue Date & 2011 \\
\hline Doc URL & http://hdl.handle.net/2115/47436 \\
\hline Type & article \\
\hline File Information & jofphysicalchemistryC_115.pdf \\
\hline
\end{tabular}

Instructions for use 


\title{
Design of Mesoporous Silica/Cytosine-Phosphodiester-Guanine Oligodeoxynucleotide Complexes To Enhance Delivery Efficiency
}

\author{
Yufang Zhu, ${ }^{*} \dagger$ Wenjun Meng, ${ }^{\ddagger}$ Xianglan Li, ${ }^{\S}$ Hong Gao, ${ }^{\dagger}$ and Nobutaka Hanagata $*, \ddagger, \S$ \\ International Center for Young Scientists, National Institute for Materials Science, 1-2-1 Sengen, Tsukuba, \\ Ibaraki 305-0047, Japan, School of Life Science, Hokkaido University, N10W8, Kita-ku, Sapporo 060-0812, Japan, \\ and Nanotechnology Innovation Center, National Institute for Materials Science, 1-2-1 Sengen, Tsukuba, \\ Ibaraki, 305-0047, Japan
}

Received: October 5, 2010; Revised Manuscript Received: November 23, 2010

\begin{abstract}
We developed a potential cytosine-phosphodiester-guanine oligodeoxynucleotide (CpG ODN) delivery system combining amino-modified mesoporous silica SBA-15 $\left(\mathrm{SBA}-\mathrm{NH}_{2}\right)$ particles with polycation poly(allylamine hydrochloride) (PAH) to form SBA-ODN-PAH complexes. Stability, cell uptake, in vitro cytotoxicity, and the nuclear factor $\kappa \mathrm{B}(\mathrm{NF}-\kappa \mathrm{B})$ activity of the SBA-ODN-PAH complexes were evaluated. Gel electrophoresis indicated that the SBA-ODN-PAH complexes exhibited enhanced serum stability due to the dual protection effects of the SBA-NH 2 particles and the PAH coating. The SBA-ODN-PAH complexes were taken up by 293XL-hTLR9 cells and little cytotoxicity was expressed in a 3-[4,5-dimethylthiazol-2-yl]-2,5-diphenyltetrazolium bromide assay. Most importantly, the SBA-ODN-PAH complexes significantly enhanced NF- $\kappa$ B activity, stimulated by interaction between the internalized CpG ODN and Toll-like receptor 9, compared to free $\mathrm{CpG}$ ODN and SBA-ODN complexes. Thus, SBA-ODN-PAH complexes provide a promising strategy for enhancing the delivery efficiency of CpG ODN.
\end{abstract}

\section{Introduction}

Cytosine-phosphodiester-guanine oligodeoxynucleotides (CpG ODNs) are potent immunostimulators recognized by the innate immune system through interaction with Toll-like receptor 9 (TLR9), located inside the endocytic compartment of antigenpresenting cells (APCs). ${ }^{1-3}$ Therefore, $\mathrm{CpG}$ ODNs have significant potential for treatment of a wide variety of diseases including cancer, asthma, allergies, and infectious diseases. ${ }^{4-7}$ The stability of CpG ODNs is important in their ability to trigger activation and maturation of APCs and promote increased expression of antibodies. However, free $\mathrm{CpG}$ ODNs have poor stability and are prone to nuclease degradation and rapid clearing from the bloodstream, which renders them inactive in the free form. To enhance their activity, a variety of strategies have been employed to minimize CpG ODN degradation. ${ }^{8-15}$ Chemical modification, such as substitution of the phosphodiester linkage with a phosphorothioate, is one of the most effective and reliable methods for increasing the biological activity of CpG ODNs, due to increased resistance to enzymatic degradation. ${ }^{8,9}$ Recently, increasing efforts have been made to use various particles as vehicles for gene delivery, such as biodegradable microparticles, liposomes, and inorganic nanoparticles, due to their ability to provide protection against degradation. ${ }^{10-17}$ For example, Whitmore et al. and Dow et al. demonstrated that lipid-encapsulated CpG ODNs trigger significant antitumor activity against established tumors in a mouse lung metastatic model, resulting in inhibition of tumor growth. ${ }^{18-20}$ However, chemically modified CpG ODNs and certain other CpG ODN delivery systems with

\footnotetext{
* Corresponding authors: Yufang Zhu, zjf2412@163.com; Nobutaka Hanagata, HANAGATA.Nobutaka@nims.go.jp.

${ }^{\dagger}$ International Center for Young Scientists, National Institute for Materials Science.

* School of Life Science, Hokkaido University.

${ }^{\S}$ Nanotechnology Innovation Center, National Institute for Materials Science.
}

particles as vehicles may cause toxic effects. Therefore, it is still challenging to develop suitable vehicles for $\mathrm{CpG}$ ODN delivery.

Mesoporous silica was first synthesized by Kresge and coworkers in $1992 .{ }^{21}$ Due to its high specific surface area, large pore volume, well-defined pore surface, biocompatibility, and nontoxicity, mesoporous silica could serve as an ideal vehicle for drugs, proteins, and biogenic molecules. ${ }^{22-27}$ Recent studies have confirmed the possibility of using mesoporous silica as a delivery vehicle for nucleic acid based reagents. ${ }^{27-35}$ Radu et al. reported a novel gene transfection system based on secondgeneration polyamidoamine dendrimers grafted to MCM-41 mesoporous silica nanospheres, which was able to be taken up by cells; the transfection efficacy was significantly enhanced compared to other commercial transfection reagents. ${ }^{28}$ Park et al. prepared mannosylated polyethylenimine-coupled mesoporous silica nanoparticles bonded to plasmid DNA, and the mesoporous silica/DNA complexes demonstrated enhanced transfection efficiency through receptor-mediated endocytosis via the mannose receptor in Raw 264.7 and HeLa cells. ${ }^{29}$ Torney et al. designed a mesoporous silica nanoparticle (MSN) system, involving encapsulation of chemicals by bonding gold nanoparticle caps to the openings of the mesopores and adsorbing plasmid DNA onto the surface of the MSN, which was able to simultaneously transport DNA and chemicals into isolated plant cells and trigger gene expression. ${ }^{30}$ Chen et al. reported a similar MSN system that codelivered doxorubicin and Bcl-2 siRNA to multidrug-resistant cancer cells to enhance chemotherapeutic efficacy. ${ }^{31}$ To date, only a few studies have been conducted on gene transfection using mesoporous silica as a vehicle. To the best of our knowledge, no study using mesoporous silica as a vehicle for CpG ODN delivery, triggering interaction with TLR9 to induce immune activity, has previously been reported.

In this study, we report for the first time a potential $\mathrm{CpG}$ ODN delivery system based on $\mathrm{SBA}-\mathrm{NH}_{2}$ mesoporous silica 
particles and polycation poly(allylamine hydrochloride) (PAH) polyelectrolyte to form SBA-ODN-PAH complexes. The preparation of the SBA-ODN-PAH complexes involves bonding the $\mathrm{CpG}$ ODN to $\mathrm{SBA}-\mathrm{NH}_{2}$ particles to form SBA-ODN complexes and subsequently coating PAH polyelectrolyte onto the SBAODN complexes to further protect the CpG ODN. Serum stability, cell uptake, in vitro cytotoxicity, and the nuclear factor $\kappa \mathrm{B}(\mathrm{NF}-\kappa \mathrm{B})$ activity of the SBA-ODN-PAH complexes were also investigated in detail.

\section{Experimental Details}

Preparation of Amino-Modified SBA-15 (SBA-NH $)$ Particles. Mesoporous SBA-15 particles were prepared as reported previously, with minor modifications. ${ }^{36}$ Four grams of P123 $\left(\mathrm{EO}_{20} \mathrm{PO}_{70} \mathrm{EO}_{20}\right)$ was added to a mixture of $130 \mathrm{~mL}$ of $\mathrm{H}_{2} \mathrm{O}$ and $21 \mathrm{~mL}$ of $\mathrm{HCl}$ aqueous solution $(35-37 \%)$ in a polyethylene bottle, and the mixture was stirred at $39{ }^{\circ} \mathrm{C}$ until the $\mathrm{P} 123$ was completely dissolved. Subsequently, 9.2 of $\mathrm{mL}$ tetraethyl orthosilicate was added to this solution under vigorous stirring. After $5 \mathrm{~min}$ of stirring, the mixture was held under static conditions at $39{ }^{\circ} \mathrm{C}$ for $24 \mathrm{~h}$, followed by $24 \mathrm{~h}$ at $100{ }^{\circ} \mathrm{C}$. The solid products were collected by filtration, washed with water, dried, and calcined at $530{ }^{\circ} \mathrm{C}$ in flowing air to obtain the SBA15 particles. To obtain the SBA- $\mathrm{NH}_{2}$ particles, $1.0 \mathrm{~g}$ of the SBA15 particles was added to $100 \mathrm{~mL}$ of ethanol containing 1.0 $\mathrm{mL}$ of (3-aminopropyl)triethoxysilane (APTES, $\left(\mathrm{C}_{2} \mathrm{H}_{5} \mathrm{O}\right)_{3} \mathrm{SiCH}_{2-}$ $\mathrm{CH}_{2} \mathrm{CH}_{2} \mathrm{NH}_{2}$ ). After being stirred at room temperature for $24 \mathrm{~h}$, the mixture was extensively washed with ethanol and dried at $80{ }^{\circ} \mathrm{C}$

Preparation of SBA-ODN-PAH Complexes. $\mathrm{SBA}^{-\mathrm{NH}_{2}}$ particles were dispersed in sterilized water to a concentration of $2 \mathrm{mg} / \mathrm{mL}$ and stored at $4{ }^{\circ} \mathrm{C}$ until use. Natural phosphodiester (PD) CpG ODN 2006 (sequence: 5'-TCGTCGTTTTGTCGTTTTGTCGTT-3'; Greiner Bio-One) was diluted in sterilized water to a concentration of $100 \mathrm{mM}$ and stored at $-20{ }^{\circ} \mathrm{C}$ until use. To prepare the SBA-ODN-PAH complexes, an SBA-NH suspension was obtained by ultrasonic treatment for $20 \mathrm{~min}$. Six microliters of ODN 2006 was added to $40 \mu \mathrm{L}$ of SBA-NH suspension, and the resulting mixture was continuously shaken at $4{ }^{\circ} \mathrm{C}$ overnight. These SBA/CpG ODN complexes are termed SBA-ODN complexes hereafter. Subsequently, $50 \mu \mathrm{L}$ of PAH solution $(1 \mathrm{mg} / \mathrm{mL}$ in $0.5 \mathrm{M} \mathrm{NaCl})$ was added to the SBAODN complexes. After shaking at $4{ }^{\circ} \mathrm{C}$ for $4 \mathrm{~h}$, the mixture was washed with sterilized water twice to obtain the SBA-ODNPAH complexes.

Characterization Methods. Scanning electron microscopy (SEM) was carried out using a JSM-7001F field emission scanning electron microscope (JEOL). Transmission electron microscopy (TEM) was performed using a JEM-2000FX electron microscope (JEOL) operated at an acceleration voltage of $200 \mathrm{kV}$. Fourier transform infrared (FTIR) spectra were obtained using a Nicolet 4700 spectrometer (Thermo Fisher Scientific). Nitrogen adsorption-desorption isotherms were obtained using a NOVA 4200e surface area analyzer (Quantachrome) at $-196{ }^{\circ} \mathrm{C}$ under continuous adsorption conditions. Zeta potential measurements were conducted using a laser electrophoresis zeta-potential analyzer (LEZA-600, Otsuka, Japan). UV-vis adsorption measurements were carried out using a NanoDrop 2000 spectrophotometer (Thermo Scientific).

Determination of CpG ODN Bonding. Bonding of $\mathrm{CpG}$ $\mathrm{ODN}$ to $\mathrm{SBA}-\mathrm{NH}_{2}$ particles was confirmed by gel electrophoresis using a $15 \%$ TBE-Urea Gel (Invitrogen). SBA- $\mathrm{NH}_{2}$ particles were reacted with $\mathrm{CpG}$ ODN at various weight ratios from 5 to $50 \mathrm{SBA}-\mathrm{NH}_{2} / \mathrm{CpG}$ ODN. After centrifugation (15000 rpm, 10 min), the supernatant was recovered and loaded into the gel, and electrophoresis was carried out at $180 \mathrm{~V}$ for 55 min running with a $1 \times$ TBE buffer according to the manufacturer's instructions. Ethidium bromide was used to visualize CpG ODN using a UV transilluminator (Dolphin-Doc, Kurabo industries Ltd.) at $312 \mathrm{~nm}$.

The amounts of CpG ODN bonded to the SBA-ODN and SBA-ODN-PAH complexes were obtained by determination of the residual $\mathrm{CpG}$ ODN concentration in the supernatant recovered after centrifugation using a NanoDrop 2000 spectrophotometer at $260 \mathrm{~nm}$. The bonded amounts were calculated as follows

$$
Q=\left(C_{0} V_{0}-C_{1} V_{1}\right) / m
$$

where $C_{0}$ and $C_{1}$ are the concentrations of initial CpG ODN and residual $\mathrm{CpG}$ ODN, $V_{0}$ and $V_{1}$ are the volumes of initial CpG ODN and the supernatant, and $m$ is the weight of the SBA$\mathrm{NH}_{2}$ particles.

Stability of the SBA-ODN-PAH Complexes. Forty-three micrograms of the SBA-ODN-PAH complexes containing $3 \mu \mathrm{g}$ of $\mathrm{CpG}$ ODN was incubated in a medium containing $20 \%$ fetal bovine serum (FBS; $23 \mu \mathrm{L}$ ) at $37^{\circ} \mathrm{C}$. After a 1 or $3 \mathrm{~h}$ digestion, the SBA-ODN-PAH complexes were separated after washing with sterilized water and subsequently dispersed in $10 \mu \mathrm{L}$ of sterilized water. The suspension was then loaded into the $15 \%$ TBE-Urea gel, and electrophoresis was carried out at $180 \mathrm{~V}$ for 55 min running with a $1 \times$ TBE buffer, according to the manufacturer's instructions.

Cell Culture. 293XL-hTLR9 cells stably expressing human TLR9 were purchased from InvivoGen. The cells were grown in DMEM medium supplemented with $10 \% \mathrm{FBS}, 50 \mathrm{U} / \mathrm{mL}$ penicillin, $50 \mathrm{mg} / \mathrm{mL}$ streptomycin, $100 \mu \mathrm{g} / \mathrm{mL}$ Normocin, and $10 \mu \mathrm{g} / \mathrm{mL}$ Blasticidin at $37^{\circ} \mathrm{C}$ in humidified air containing $5 \%$ $\mathrm{CO}_{2}$. The cells were seeded on 24-well culture plates for transfection and stimulation experiments.

Cell Uptake of SBA-ODN-PAH Complexes. 3'-Fluorescein isothiocyanate (FITC)-labeled $\mathrm{CpG}$ ODN (ODN-FITC) was loaded onto the SBA-NH 2 particles to form SBA-ODN-FITC and SBA-ODN-FITC-PAH complexes. Free ODN-FITC, SBA$\mathrm{NH}_{2}$ particles, SBA-ODN-FITC, and SBA-ODN-FITC-PAH complexes were used to stimulate the cells. In a typical procedure, $1 \times 10^{5} 293$ XL-TLR9 cells were seeded in a Petri dish with a glass bottom (growth area $\sim 8.7 \mathrm{~cm}^{2}$ ) and cultured for $48 \mathrm{~h}$. Subsequently, $40 \mu \mathrm{L}$ of SBA-NH$H_{2}$ suspension, $46 \mu \mathrm{L}$ of SBA-ODN-FITC complex (6 $\mu \mathrm{L}$ of ODN-FITC), $46 \mu \mathrm{L}$ of SBA-ODN-FITC-PAH complex ( $6 \mu \mathrm{L}$ of ODN-FITC), or $6 \mu \mathrm{L}$ of free ODN-FITC was added to the Petri dishes. After $4 \mathrm{~h}$ of incubation, the cells were washed with PBS to remove the remaining particles and dead cells. The cells were then fixed with $4 \%$ paraformaldehyde for $20 \mathrm{~min}$. After washing 3 times with PBS, the cells were observed under an SP5 confocal laser scanning microscope (CLSM; Leica).

In Vitro Cytotoxicity Assay. The in vitro cytotoxicities of the SBA-ODN-PAH complexes were assessed using 3-[4,5dimethylthiazol-2-yl]-2,5-diphenyltetrazolium bromide (MTT) assays. To allow the cells to attach, 7000 cells were seeded in 96-well plates for $24 \mathrm{~h}$ and then exposed to free CpG ODN, SBA-NH $\mathrm{N}_{2}$ particles, SBA-ODN, or SBA-ODN-PAH complexes in $5 \% \mathrm{CO}_{2}$ at $37{ }^{\circ} \mathrm{C}$. After a $24 \mathrm{~h}$ incubation, the medium containing free $\mathrm{CpG}$ ODN, SBA-NH $\mathrm{N}_{2}$ particles, SBA-ODN, or SBA-ODN-PAH complexes was removed, and $200 \mu \mathrm{L}$ of MTT solution (diluted in culture medium to a final concentration of $1 \mathrm{mg} / \mathrm{mL}$ ) was added and incubated for another $4 \mathrm{~h}$. The medium 

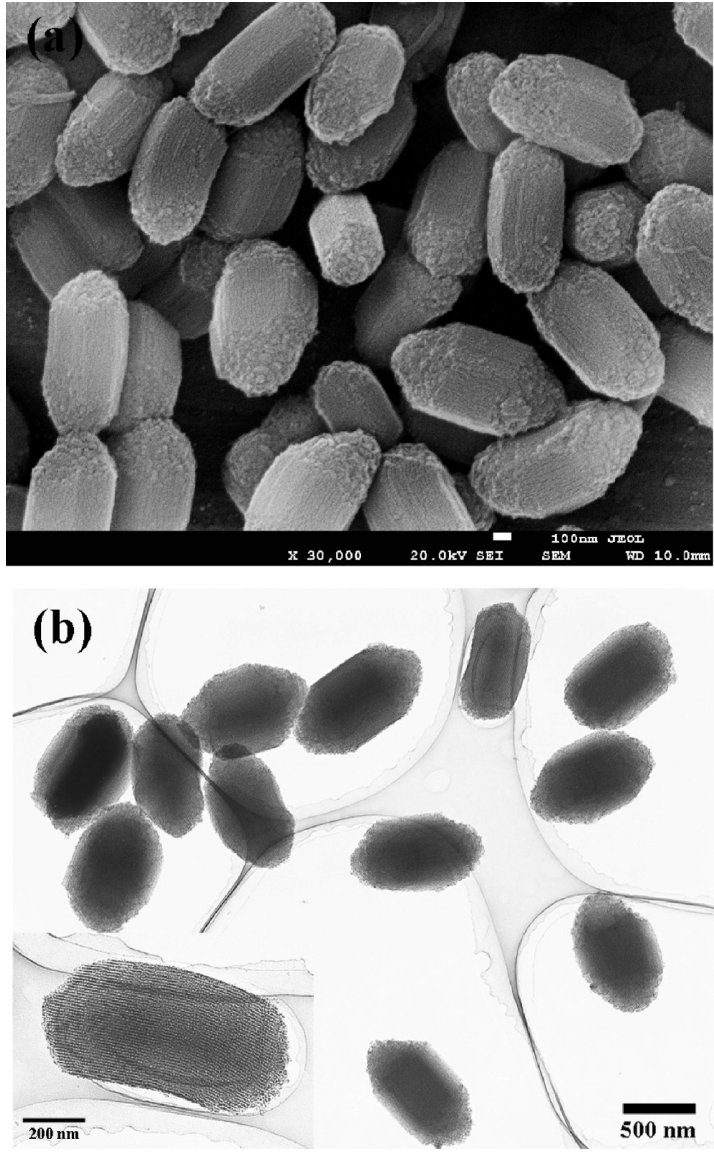

Figure 1. SEM (a) and TEM (b) images of $\mathrm{SBA}-\mathrm{NH}_{2}$ particles.

was then replaced with $200 \mu \mathrm{L}$ dimethyl sulfoxide (DMSO), and absorbance was monitored using a microplate reader (MTP$880 \mathrm{Lab}$, Corona) at a wavelength of $570 \mathrm{~nm}$. Cytotoxicity was expressed as the percentage of viable cells compared to that of the untreated control cells.

NF- $\kappa$ B Luciferase Assay. To monitor transient NF- $\kappa$ B activity, 293XL-hTLR9 cells were seeded at $1.5 \times 10^{5}$ cells per well and transiently transfected with pNiFty-Luc (a TLR9signaling reporter plasmid; InvivoGen) and pGL4.74 (Renilla luciferase gene contained plasmid; Promega) using LyoVec (InvivoGen). After a $24 \mathrm{~h}$ culture, the cells were stimulated with free $\mathrm{CpG}$ ODN, SBA-NH $\mathrm{N}_{2}$ particles, SBA-ODN, or SBA-ODNPAH complexes for another $24 \mathrm{~h}$. The stimulated cells were lysed using a passive lysis buffer, and the lysates were assayed for luciferase activity using a TD-20/20 luminometer (Promega) according to the manufacturer's instructions. The data are expressed as an $n$-fold increase in NF- $\kappa \mathrm{B}$ activity over the medium control.

\section{Results and Discussion}

Preparation of Amino-Modified SBA-15 (SBA- $\mathrm{NH}_{2}$ ) Particles. Figure 1 shows SEM and TEM images of the SBA-NH particles, which appear as highly monodisperse ricelike particles with an aspect ratio of $\sim 2$ and a diameter of $\sim 500 \mathrm{~nm}$. Twodimensional hexagonal mesopores with well-ordered channels can clearly be observed in the high-magnification TEM image (inset, Figure 1b). The $\mathrm{N}_{2}$ adsorption-desorption curve exhibits a type IV isotherm (Figure 2a). The type H1 hysteresis loop in the mesoporous range is characteristic of cylindrical pores and the $p 6 \mathrm{~mm}$ mesostructure, which is consistent with the TEM result and suggests that amino modification did not destroy the
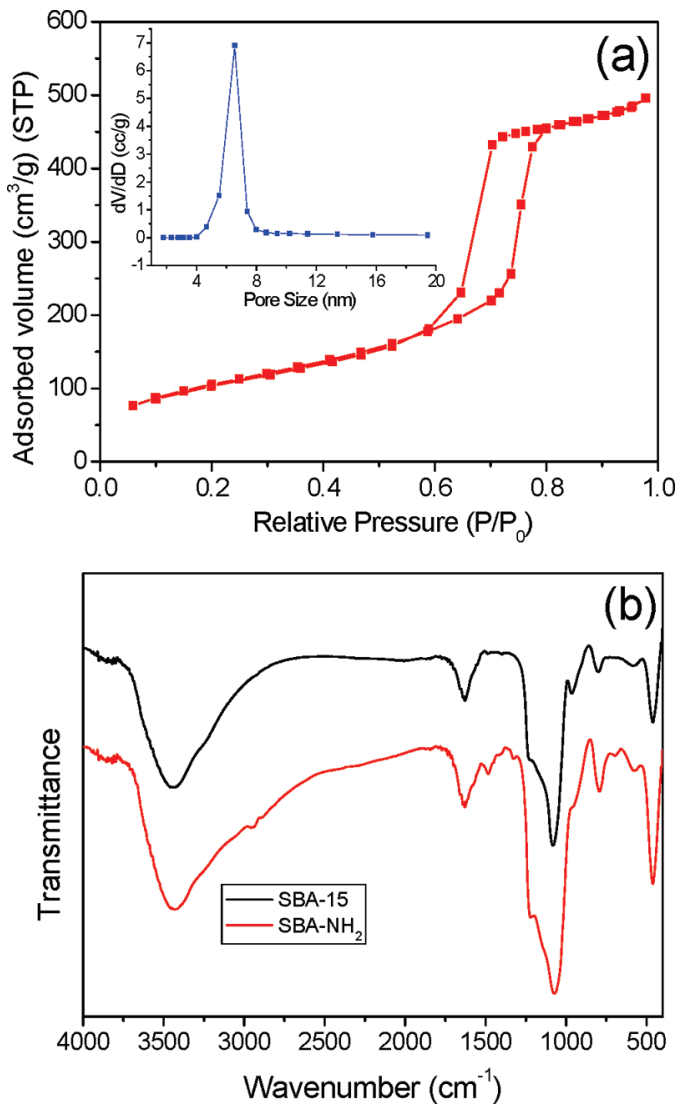

Figure 2. (a) $\mathrm{N}_{2}$ adsorption-desorption isotherm for $\mathrm{SBA}-\mathrm{NH}_{2}$ particles and the corresponding pore size distribution. (b) FTIR spectra of SBA-15 and SBA-NH 2 particles.

mesoporous channels. The BET surface area of the SBA- $\mathrm{NH}_{2}$ particles was as high as $423 \mathrm{~m}^{2} / \mathrm{g}$, and the single point adsorption total volume at $P / P_{0}=0.90$ was $0.846 \mathrm{~cm}^{3} / \mathrm{g}$. The pore size distribution calculated from the desorption branches using the BJH (Barret-Joyner-Halenda) method exhibited a narrow distribution with a peak at $6.8 \mathrm{~nm}$, allowing $\mathrm{CpG}$ ODN to diffuse into the channels and bond to the pore walls, as ODN 2006 is a synthetic oligonucleotide that contains only 24 bases.

FTIR spectra for the SBA-15 and SBA- $\mathrm{NH}_{2}$ particles are shown in Figure 2b. After SBA-15 was modified with amino groups, well-resolved vibrational peaks can clearly be observed at 1326 and $1390 \mathrm{~cm}^{-1}$ assigned to the $\mathrm{C}-\mathrm{N}$ stretching bands, as well as vibrational peaks at 2940,2885 , and $1480 \mathrm{~cm}^{-1}$ assigned to symmetric stretching and bending of $\mathrm{C}-\mathrm{H}$ groups. In contrast, the $\mathrm{Si}-\mathrm{OH}$ band at $960 \mathrm{~cm}^{-1}$ in the SBA- 15 spectra became significantly weaker after amino group modification. These results suggest that amino groups have been grafted onto the SBA-15 particles. The zeta potential measurements further confirmed amino modification of the SBA-15 particles. The zeta potential of the SBA-15 particles was $-27.3 \mathrm{mV}$, while that of the SBA- $\mathrm{NH}_{2}$ particles was $6.7 \mathrm{mV}$ due to the grafting of positively charged amino groups onto the SBA-15 particles (Figure 3). Therefore, the SBA- $\mathrm{NH}_{2}$ particles were able to bind to the negatively charged $\mathrm{CpG}$ ODN to form SBA-ODN complexes through electrostatic interaction.

Preparation and Stability of SBA-ODN-PAH Complexes. Bonding of $\mathrm{CpG}$ ODN onto SBA- $\mathrm{NH}_{2}$ particles was confirmed using TBE-Urea gel electrophoresis, UV-vis spectra, and zeta potential measurements. As shown in Figure 4, the CpG ODN band in the supernatant became weaker with an increase in the weight ratio and disappeared at a weight ratio of $\geq 15$, suggesting 


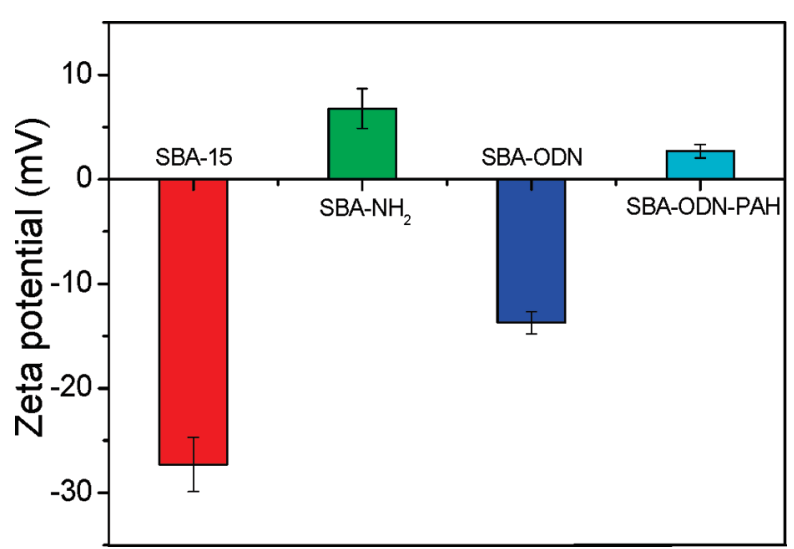

Figure 3. Zeta potentials of SBA-15, SBA- $\mathrm{NH}_{2}$ particles, SBA-ODN, and SBA-ODN-PAH complexes.

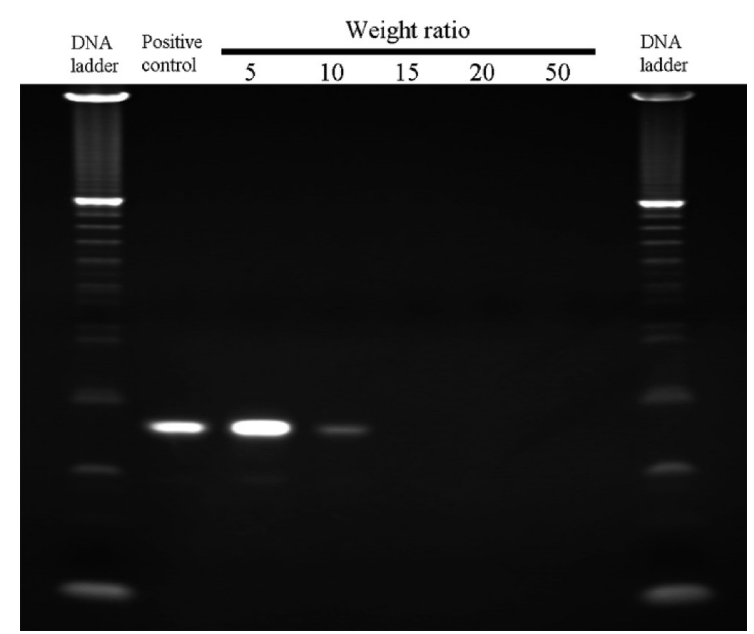

Figure 4. Gel electrophoresis of the supernatants after the interaction between $\mathrm{CpG}$ ODN and SBA-NH $\mathrm{N}_{2}$ particles at various weight ratios using 15\% TBE-Urea gel in TBE running buffer.

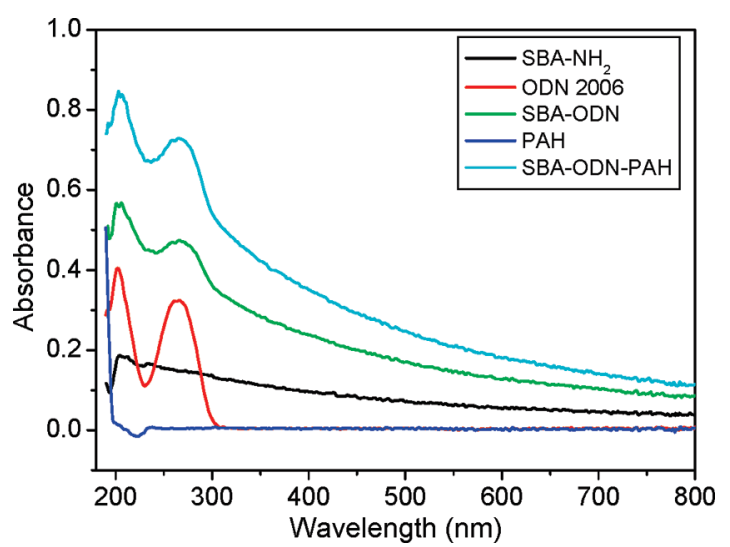

Figure 5. UV-vis spectra of free $\mathrm{CpG}$ ODN, $\mathrm{SBA}-\mathrm{NH}_{2}$ particles, SBA-ODN, and SBA-ODN-PAH complexes.

that $\mathrm{CpG}$ ODN was able to bind to the $\mathrm{SBA}-\mathrm{NH}_{2}$ particles due to the interaction between the negatively charged $\mathrm{CpG}$ ODN and the positively charged $\mathrm{SBA}-\mathrm{NH}_{2}$ particles, and that all of the $\mathrm{CpG}$ ODN molecules were bound to $\mathrm{SBA}-\mathrm{NH}_{2}$ particles at a weight ratio of $\geq 15$. The zeta potential of the particles decreased from 6.7 to $-13.7 \mathrm{mV}$ after $\mathrm{CpG}$ ODN bonding (Figure 3), and the adsorption bands for CpG ODN appeared on the UV-vis spectrum for the SBA-ODN complexes (Figure 5), also confirming that $\mathrm{CpG} \mathrm{ODN}$ bonded to the $\mathrm{SBA}-\mathrm{NH}_{2}$ particles to form SBA-ODN complexes. After coating the SBAODN complexes with $\mathrm{PAH}$, the $\mathrm{UV}-$ vis spectrum retained the

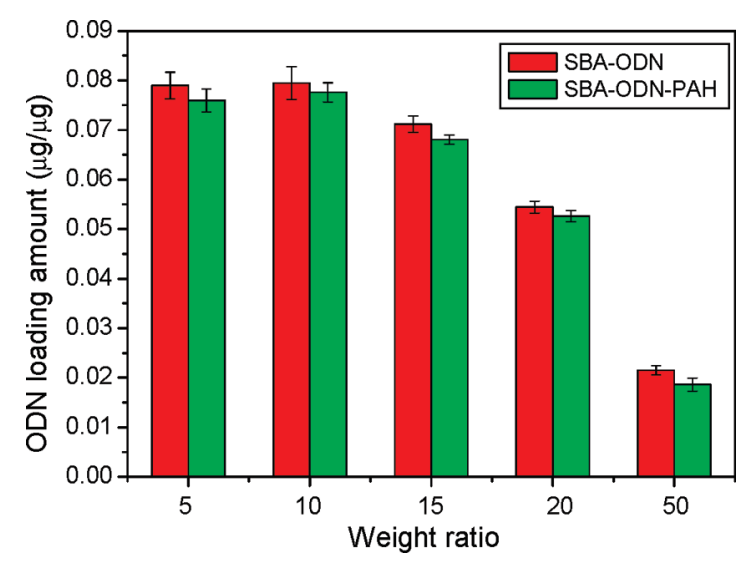

Figure 6. CpG ODN bonded amounts for SBA-ODN and SBA-ODN$\mathrm{PAH}$ complexes at various weight ratios.

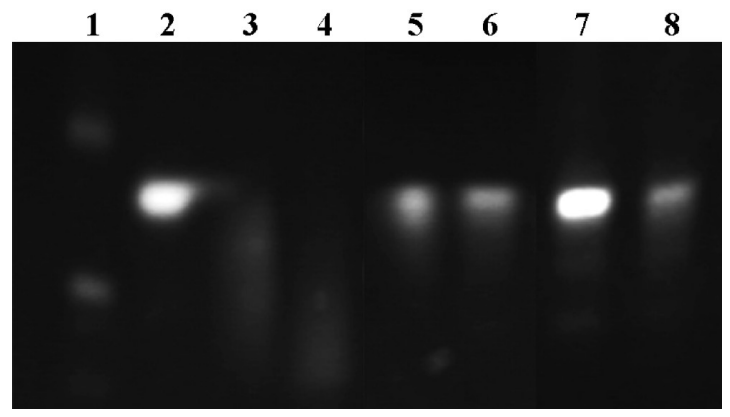

Figure 7. Stability of free CpG ODN, SBA-ODN, and SBA-ODNPAH complexes in 20\% serum-containing media: lane 1 for DNA ladder; lane 2 for undigested $\mathrm{CpG}$ ODN; lanes 3 and 4 for free $\mathrm{CpG}$ ODN after 1 and $3 \mathrm{~h}$ digestions; lanes 5 and 6 for SBA-ODN complexes after 1 and $3 \mathrm{~h}$ digestions; lanes 7 and 8 for SBA-ODN-PAH complexes after 1 and $3 \mathrm{~h}$ digestions. (The weight ratio of particle/ODN is 15 .)

UV adsorption bands for CpG ODN (Figure 5), suggesting that $\mathrm{CpG}$ ODN was still bound to the SBA-NH 2 particles after the PAH coating process. The SBA-ODN-PAH complexes became positive charged $(2.7 \mathrm{mV})$ after $\mathrm{PAH}$ coating (Figure 3 ), indicating that the positively charged PAH bonded to the SBAODN complexes through interaction with the negatively charged CpG ODN. This result suggests that the SBA-ODN-PAH complexes may exhibit much higher stability due to the introduction of the $\mathrm{PAH}$ coating protecting $\mathrm{CpG}$ ODN from degradation.

The amounts of CpG ODN bonded to the SBA-ODN and SBA-ODN-PAH complexes were measured immediately after CpG ODN bonding to the $\mathrm{SBA}-\mathrm{NH}_{2}$ particles and $\mathrm{PAH}$ coating of the SBA-ODN complexes. The particles were separated by centrifugation, and the retained $\mathrm{CpG}$ ODN in the supernatant was determined by UV spectrophotometry (Figure 6). The bonded amounts were very similar at weight ratios of 5 and 10 for both SBA-ODN and SBA-ODN-PAH complexes due to the saturated bonding of $\mathrm{CpG}$ ODN. The bonded amounts decreased gradually as the weight ratio increased above 15 . Furthermore, the bonded amounts for the SBA-ODN-PAH complexes were slightly lower than those of the SBA-ODN complexes at the same weight ratios, which may be attributed to slight leaching of $\mathrm{CpG}$ ODN from the particle surfaces during the PAH coating process.

Serum stabilities of free CpG ODN, SBA-ODN, and SBAODN-PAH complexes were tested in $20 \%$ serum-containing medium for $3 \mathrm{~h}$ using gel electrophoresis. In Figure 7, lane 2 shows undigested free $\mathrm{CpG}$ ODN, lanes 3 and 4 show free $\mathrm{CpG}$ ODN after 1 and $3 \mathrm{~h}$ digestions, lanes 5 and 6 show SBA- 

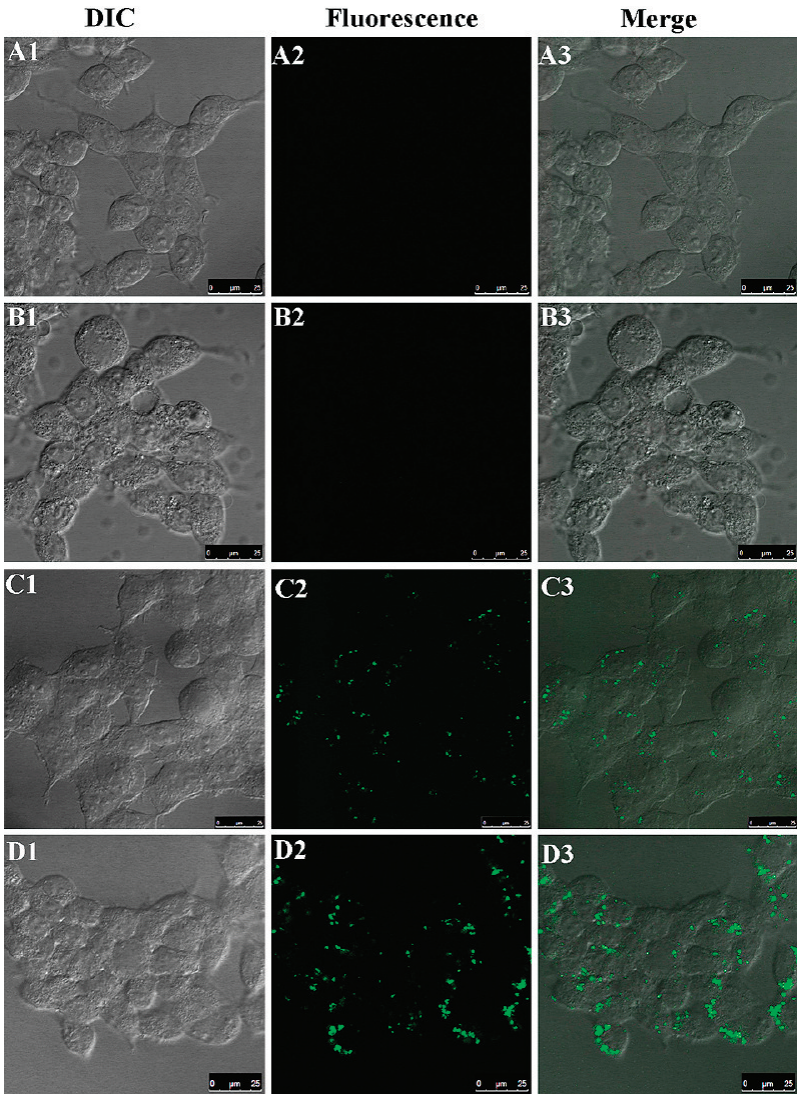

Figure 8. Confocal microscope images of 293XL-hTLR9 cells after $4 \mathrm{~h}$ of incubation with free $\mathrm{CpG}$ ODN (A1-3), $\mathrm{SBA}^{-\mathrm{NH}_{2}}$ particles (B1-3), SBA-ODN complexes (C1-3), and SBA-ODN-PAH complexes (D1-3). (The weight ratio of particle/ODN is 15 .)

ODN complexes after 1 and $3 \mathrm{~h}$ digestions, and lanes 7 and 8 show SBA-ODN-PAH complexes after 1 and $3 \mathrm{~h}$ digestions. Free $\mathrm{CpG}$ ODN was degraded in the serum containing medium after a $1 \mathrm{~h}$ digestion. For the SBA-ODN and SBA-ODN-PAH complexes, the $\mathrm{CpG}$ ODN bands were clearly observed after a $3 \mathrm{~h}$ digestion, indicating that the SBA-ODN and SBA-ODNPAH complexes were able to protect $\mathrm{CpG}$ ODN against degradation by nucleases. Furthermore, after a $1 \mathrm{~h}$ digestion at the same concentration of the complexes, the SBA-ODN-PAH complexes exhibited much higher $\mathrm{CpG}$ ODN concentrations than did the SBA-ODN complexes, suggesting that the SBAODN-PAH complexes had much higher serum stability than the SBA-ODN complexes. These results may be attributed to the dual protection effects of the $\mathrm{SBA}-\mathrm{NH}_{2}$ particles and the PAH coating. Enhanced serum stability of CpG ODN would be useful for obtaining greater in vitro and in vivo immune responses.

Cell Uptake, Cytotoxicity, and NF- $\kappa$ B Activity of the SBAODN-PAH Complexes. Cell uptake of CpG ODN is important for triggering the immune response through interaction with TLR9. To investigate the cellular internalization of SBA-ODNPAH complexes by 293XL-hTLR9 cells, 3'-Fluorescein isothiocyanate (FITC)-labeled CpG ODN (ODN-FITC) was loaded onto the $\mathrm{SBA}-\mathrm{NH}_{2}$ particles to form SBA-ODN-FITC and SBAODN-FITC-PAH complexes. Then free ODN-FITC, SBA-NH particles, SBA-ODN-FITC, and SBA-ODN-FITC-PAH complexes were incubated with 293XL-hTLR9 cells for $4 \mathrm{~h}$. As shown in Figure 8, green fluorescence from the SBA-ODNFITC and SBA-ODN-FITC-PAH complexes were distributed in the cells and primarily located near cell membranes, which suggests that most of the SBA-ODN-FITC and SBA-ODN-

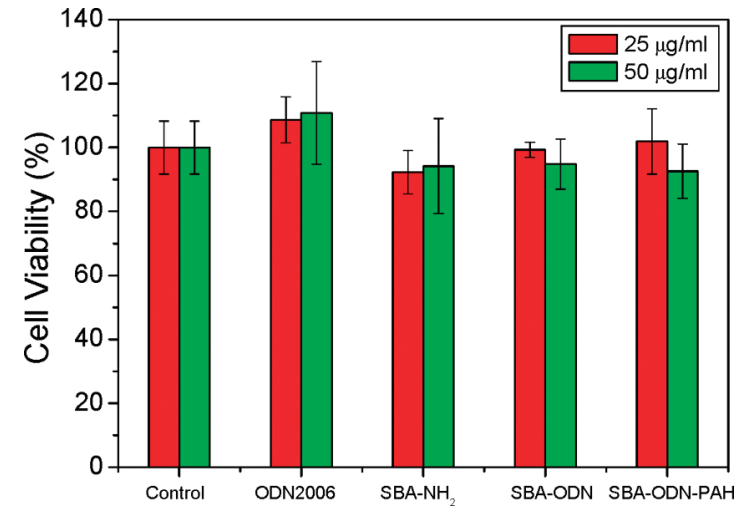

Figure 9. Viabilities of 293XL-hTLR9 cells measured by MTT assay for SBA-NH ${ }_{2}$ particles, SBA-ODN, and SBA-ODN-PAH complexes. (The weight ratio of particle/ODN is 15 .)

FITC-PAH complexes were internalized into the endosomes or lysosomes after a $4 \mathrm{~h}$ incubation. Furthermore, at the same incubated concentration of the complexes, green fluorescence in cells stimulated with the SBA-ODN-FITC-PAH complexes was much higher than that in cells stimulated with the SBAODN-FITC complexes, indicating that a greater amount of the SBA-ODN-FITC-PAH complexes was internalized into the 293XL-hTLR9 cells. The positive charge of the SBA-ODNFITC-PAH complexes may be more effective in inducing internalization of the complexes into the cells due to the negative charge of cell membranes. In contrast, for free ODN-FITC, no green fluorescence could be observed in the cells, suggesting that free ODN-FITC was degraded in the culture medium or the cells or that lower cell uptake of free ODN-FITC made it difficult to observe the green fluorescence. Therefore, bonding $\mathrm{CpG}$ ODN to $\mathrm{SBA}-\mathrm{NH}_{2}$ particles and subsequent coating of PAH to form SBA-ODN-PAH complexes appears to significantly enhance the efficiency of cell uptake of CpG ODN, promoting interaction of CpG ODN with TLR9 and triggering the immune response.

To evaluate in vitro cytotoxicity of SBA-ODN-PAH complexes to 293XL-hTLR9 cells, cell viability tests were performed using MTT assay. The effects of the SBA-ODN-PAH complexes on the viability of 293XL-hTLR9 cells were shown in Figure 9. Cell viabilities for the $\mathrm{SBA}-\mathrm{NH}_{2}$ particles, SBA-ODN and SBA-ODN-PAH complexes were very similar to that of the control group. Compared to the SBA- $\mathrm{NH}_{2}$ particles, the SBAODN-PAH complexes resulted in no apparent decrease in cell viability. These results suggest that the SBA-ODN-PAH complexes have little cytotoxic effect on 293XL-hTLR9 cells. Therefore, the SBA-ODN-PAH complexes could be used as nonviral carriers for $\mathrm{CpG}$ ODN delivery.

CpG ODN in the endosomes or lysosome can bind to TLR9 after endocytosis, activating NF- $\kappa \mathrm{B}$. This initiates the induction of multiple cytokines and chemokines and modulates the cellular inflammatory response. ${ }^{2}$ Therefore, enhancement of NF- $\kappa \mathrm{B}$ activity is very important for heightening the immune response. To evaluate the biological activity of the SBA-ODN-PAH complexes, NF- $\kappa \mathrm{B}$ luciferase activity assays were performed on 293XL-hTLR9 cells. Free CpG ODN and the $\mathrm{SBA}-\mathrm{NH}_{2}$ carrier were used as controls. As shown in Figure 10, the NF$\kappa \mathrm{B}$ luciferase activities of the SBA-ODN and SBA-ODN-PAH complexes were significantly enhanced compared to that of free CpG ODN. The SBA-ODN and SBA-ODN-PAH complexes were able to protect $\mathrm{CpG}$ ODN from being degraded during cell uptake of the complexes. After the complexes were internalized in the endosomes or lysosomes, the released $\mathrm{CpG}$ 


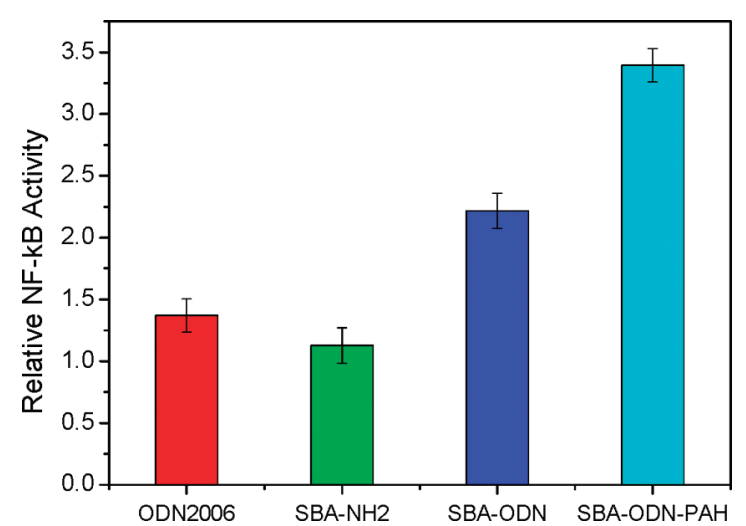

Figure 10. NF- $\kappa$ B luciferase activities of SBA-ODN and SBA-ODNPAH complexes in 293XL-hTLR9 cells. (The weight ratio of particle/ ODN is 15.)

ODN and the CpG ODN located on the surface of the complexes were able to interact with TRL 9, resulting in enhancement of $\mathrm{NF}-\kappa \mathrm{B}$ luciferase activity. Furthermore, the SBA-ODN-PAH complexes exhibited much higher $\mathrm{NF}-\kappa \mathrm{B}$ luciferase activity than the SBA-ODN complexes. The enhancement of serum stability and the efficiency of cell uptake of the SBA-ODN-PAH complexes provided more $\mathrm{CpG}$ ODN to interact with TLR9, contributing to the higher NF- $\kappa$ B luciferase activity of the SBAODN-PAH complexes. Therefore, the SBA-ODN-PAH complexes have great potential for CpG ODN delivery to enhance immune activity.

\section{Conclusions}

In this study, mesoporous silica/CpG ODN complexes (SBAODN-PAH complexes) were developed through interactions between CpG ODN and amino-modified SBA-15, followed by PAH coating. In vitro cytotoxicity measured by MTT assay indicated that the SBA-ODN-PAH complexes had no obvious cytotoxicity to 293XL-hTLR9 cells. Compared to free CpG ODN and SBA-ODN complexes, the SBA-ODN-PAH complexes exhibited higher serum stability, protecting CpG ODN from degradation, and higher efficiency of cell uptake due to the positive charge of the SBA-ODN-PAH complexes. Most importantly, $\mathrm{NF}-\kappa \mathrm{B}$ activity stimulated by the interaction between the internalized CpG ODN and TLR9 was significantly enhanced by SBA-ODN-PAH complex delivery compared to free $\mathrm{CpG}$ ODN delivery or SBA-ODN complex delivery. Therefore, the SBA-ODN-PAH complexes provide a promising strategy for enhancing the delivery efficiency of CpG ODN.

Acknowledgment. The authors gratefully acknowledge the support provided by Grant-in-Aid for Scientific Research (2256077) from the Japan Society for Promotion of Science, Key Laboratory of Inorganic and Composite New Materials of Jiangsu Province (No. Wjjqfhxc1200804), and International Center for Young Scientists, National Institute for Materials Science, Japan.

\section{References and Notes}

(1) Krieg, A. M. Nat. Rev. Drug Discovery 2006, 5, 471-484.

(2) Hemmi, H.; Takeuchi, O.; Kawai, T.; Kaisho, T.; Sato, S.; Sanjo, H.; Matsumoto, M.; Hoshino, K.; Wagner, H.; Takeda, K.; Akira, S. Nature 2000, 408, 740-745.

(3) Takeshita, F.; Leifer, C. A.; Gursel, I.; Ishii, K. J.; Takeshita, S.; Gursel, M.; Klinman, D. M. J. Immunol. 2001, 167, 3555-3558.

(4) Fonseca, D. E.; Kline, J. N. Adv. Drug Delivery Rev. 2009, 61, 256-262.

(5) Salem, A. K. Adv. Drug Delivery Rev. 2009, 61, 193-194. 204.

(6) Vollmer, J.; Krieg, A. M. Adv. Drug Delivery Rev. 2009, 61, 195-

(7) Zhou, S.; Kawakami, S.; Yamashita, F.; Hashida, M. Cancer Lett. 2010, 287, 75-81.

(8) Kurreck, J. Eur. J. Biochem. 2003, 270, 1628-1644. 528.

(9) Agrawal, S.; Zhang, Q. Curr. Opin. Chem. Biol. 1998, 2, 519-

(10) Malyala, P.; O’Hagan, D. T.; Singh, M. Adv. Drug Delivery Rev. 2009, 61, 218-225.

(11) Wilson, K. D.; de Jong, S. D.; Tam, Y. K. Adv. Drug Delivery Rev. 2009, 61, 233-242.

(12) Xiang, Y.; Yu, Q.; Qi, Z.; Du, Z.; Xu, S.; Zhang, H. J. Huazhong Univ. Sci. Technol., Med. Sci. 2007, 27, 128-130.

(13) Bianco, A.; Hoebeke, J.; Godefroy, S.; Chaloin, O.; Pantarotto, D.; Briand, J.-P.; Muller, S.; Prato, M.; Partidos, C. D. J. Am. Chem. Soc. 2005, $127,58-59$.

(14) Standley, S. M.; Mende, I.; Goh, S. L.; Kwon, Y. J.; Beaudette, T. T.; Engleman, E. G.; Fréchet, J. M. J. Bioconjugate Chem. 2007, 18, $77-83$.

(15) Rattanakiat, S.; Nishikawa, M.; Funabashi, H.; Luo, D.; Takakura, Y. Biomaterials 2009, 30, 5701-5706.

(16) Liu, T.; Yu, X.; Kan, B.; Guo, Q.; Wang, X.; Shi, S.; Guo, G.; Luo, F.; Zhao, X.; Wei, Y.; Qian, Z. J. Biomed. Nanotechnol. 2010, 6, 351-359.

(17) Guo, Q.; Shi, S.; Wang, X.; Kan, B.; Gu, Y.; Shi, X.; Luo, F.; Zhao, X.; Wei, Y.; Qian, Z. Int. J. Pharm. 2009, 379, 82-89.

(18) Whitmore, M. M.; Li, S.; Huang, L. Gene Ther. 1999, 6, 18671875

(19) Whitmore, M. M.; Li, S.; Falo Jr, L.; Huang, L. Cancer Immunol. Immunother. 2001, 50, 503-514.

(20) Dow, S. W.; Fradkin, L. G.; Liggitt, D. H.; Willson, A. P.; Heath, T. D.; Potter, T. A. J. Immunol. 1999, 163, 1552-1561.

(21) Kresge, C. T.; Leonowicz, M. E.; Roth, W. J.; Vartuli, J. C.; Beck, J. S. Nature 1992, 359, 710-712.

(22) Lebret, V.; Raehm, L.; Durand, J.-O.; SmaiiiM.; Werts, M. H. V.; Blanchard-Desce, M.; Méthy-Gonnod, D.; Dubernet, C. J. Biomed. Nanotechnol. 2010, 6, 176-180.

(23) Vallet-Regí, M.; Colilla, M.; Izquierdo-Barba, I. J. Biomed. Nanotechnol. 2008, 4, 1-15.

(24) Liu, Y.; Miyoshi, H. J. Biomed. Nanotechnol. 2008, 4, 25-32.

(25) Manzano, M.; Vallet-Regí, M. J. Mater. Chem. 2010, 20, 55935604.

(26) Hudson, S.; Cooney, J.; Magner, E. Angew. Chem., Int. Ed. 2008, $47,2-15$

(27) Hom, C.; Lu, J.; Tamanoi, F. J. Mater. Chem. 2009, 19, 63086316

(28) Radu, D. R.; Lai, C.-Y.; Jeftinija, K.; Rowe, E. W.; Jeftinija, S.; Lin, V. S.-Y. J. Am. Chem. Soc. 2004, 126, 13216-13217.

(29) Park, I. Y.; Kim, I. Y.; Yoo, M. K.; Choi, Y. J.; Cho, M.-H.; Cho, C. S. Int. J. Pharm. 2008, 359, 280-287.

(30) Torney, F.; Trewyn, B. G.; Lin, V. S.-Y.; Wang, K. Nat. Nanotechnol. 2007, 2, 295-300.

(31) Chen, A. M.; Zhang, M.; Wei, D.; Stueber, D.; Taratula, O.; Minko, T.; He, H. Small 2009, 5, 2673-2677.

(32) Qin, F.; Zhou, Y.; Shi, J.; Zhang, Y. J. Biomed. Mater. Res. 2009, 90A, 333-338.

(33) Hom, C.; Lu, J.; Liong, M.; Luo, H.; Li, Z.; Zink, J. I.; Tamanoi, F. Small 2010, 6, 1185-1190.

(34) Yiu, H. H. P.; McBain, S. C.; El Haj, A. J.; Dobson, J. Nanotechnology 2007, 18, 435601.

(35) Yiu, H. H. P.; McBain, S. C.; Lethbridge, Z. A. D.; Lees, M. R.; Dobson, J. J. Biomed. Mater. Res. 2010, 92A, 386-392.

(36) Sayari, A.; Han, B.; Yang, Y. J. Am. Chem. Soc. 2004, 126, 14348-14349.

JP109535D 